American Journal of Pharmaceutical Education 2017; 81 (2) Article 29.

\title{
RESEARCH
}

\section{Assessing Emotionally Intelligent Leadership in Pharmacy Students}

\author{
Robert C. Haight, PhD, ${ }^{\text {a }}$ Claire Kolar, PharmD, ${ }^{\text {b }}$ Michael H. Nelson, PhD, ${ }^{a}$ Kerry K. Fierke, EdD, ${ }^{\text {c }}$ \\ Brandon J. Sucher, PharmD, ${ }^{a}$ Kristin K. Janke, $\mathrm{PhD}^{\mathrm{b}}$ \\ ${ }^{\text {a }}$ Regis University, Denver, Colorado \\ ${ }^{\mathrm{b}}$ University of Minnesota, Minneapolis, Minnesota \\ ${ }^{\mathrm{c}}$ University of Minnesota, Duluth, Minnesota \\ Submitted October 5, 2015; accepted January 19, 2016; published March 25, 2017.
}

Objective. To determine the frequency distribution of pharmacy students across Emotionally Intelligent Leadership Inventory (EILI) measures.

Methods. The EILI was administered to 235 pharmacy students at two schools. The instrument was systematically compared to the 2013 CAPE Outcomes and analyzed by confirmatory factor analysis. Results. The EILI has primary connections with pharmacy competencies related to interprofessional communication and leadership. The three facets of the EILI were verified for internal consistency (Context, $\alpha=.78$; Self, $\alpha=.74$; Others, $\alpha=.79$ ). Student scores were the highest for the consciousness of self facet, with a mean score of 31.4 out of 40 .

Conclusion. The EILI shows promise as an instrument for use in assessing pharmacy students' emotional intelligence and leadership skills.

Keywords: emotional intelligence, leadership, assessment, self-awareness, CAPE outcomes

\section{INTRODUCTION}

The understanding of intelligence has evolved considerably over the past three decades. In order to better describe the modalities of intelligence, Gardner introduced the concept of multiple intelligences, which included social intelligence in 1983. ${ }^{1}$ Salovey and Mayer's ${ }^{2}$ work expands upon Gardner's work by developing emotional intelligence (EI) as a type of social intelligence. EI was subsequently popularized by Goleman. ${ }^{3}$

Emotional intelligence consists of several personal and social competencies such as self-awareness, regulation of emotions, awareness of the emotions of others, and empathy. ${ }^{4}$ Emotional intelligence has both cognitive and affective components and can be learned. ${ }^{5}$ Development of EI in pharmacy students may be of value in addressing the Center for Advancement of Pharmacy Education (CAPE) Outcomes 2013 and the Accreditation Council for Pharmacy Education (ACPE) Standards 2016 related to Personal and Professional Development (Domain 4 of CAPE 2013 Outcomes and Standard 4 of ACPE Standards 2016). ${ }^{6-8}$ More specifically, development of EI in pharmacy students is likely to foster Standards 4.1 (selfawareness) and 4.4 (professionalism). For example, empathy is both an EI competency and an important element

Corresponding Author: Robert C. Haight, 3333 Regis Blvd., H-28, Denver, CO 80221. Tel: 303-625-1259. Fax: 303-6251305. E-mail: rhaight@regis.edu of professionalism. ${ }^{9}$ However, health care professionals may actually learn to mistrust their emotions and emotionally detach from their patients in an effort to remain objective in the clinical setting. ${ }^{5,9}$ Given the links between EI, empathy, and professionalism, it is possible that development of EI in pharmacy students would enhance professionalism. In addition to connections with professionalism, a connection between communication skills and EI has been demonstrated. In studies of first- and second-year medical students, Cherry, Fletcher and O'Sullivan found a correlation between scores on objective structured clinical examination (OSCE) communication skills and student EI, suggesting that inclusion of EI in the curriculum may help students use knowledge and understanding of emotions to improve communications skills and achieve communication curricular outcomes. ${ }^{10,11}$ Emotional intelligence scores have also been positively correlated with first- and final-year medical student performance on summative assessments. ${ }^{12}$ Taken together, these findings indicate EI may be of benefit to pharmacy student performance in a doctor of pharmacy curriculum and help achieve both CAPE 2013 Outcomes and ACPE Standards 2016.

Emotional intelligence has also been proposed to play an important role in leadership development. ${ }^{13,14}$ Wong and colleagues demonstrated that the EI of leaders affects the job satisfaction and organizational citizenship 


\section{American Journal of Pharmaceutical Education 2017; 81 (2) Article 29.}

behavior of followers. ${ }^{15}$ In addition, some leadership models incorporate aspects of EI. ${ }^{16}$ For example, Kouzes and Posner's The Student Leadership Challenge, a model used for pharmacy student leadership development, has various elements that are related to EI, such as "Find Your Voice" and "Facilitate Relationships." connections, the argument can be made that EI education is an important element of pharmacy student leadership development. However, research related to the potential of EI to foster development of pharmacy student leadership abilities is needed. ${ }^{8,18}$

Use of a theoretical framework for EI research and introduction of EI into the curriculum are encouraged. ${ }^{19}$ One such framework is the Emotionally Intelligent Leadership (EIL) model, a student leadership development model that combines elements of both EI and leadership development. ${ }^{19}$ Emotionally Intelligent Leadership theory considers leadership to be dependent on the meaningful interaction of three factors: self, others, and context. The EIL theory also considers the interaction of cognitive processes, personality traits, behaviors, and competencies as predictive of leadership outcomes. ${ }^{19}$

The Emotionally Intelligent Leadership for Students Inventory (EILI), version 1, was derived from the EIL theoretical model and is a self-assessment tool for the purpose of student leadership development education. ${ }^{20}$ An important step in determining areas of focus for EI education is the identification of EI strengths and opportunities for improvement among pharmacy students. This article provides results from a study designed to examine pharmacy student EI strengths and opportunities for improvement using the EILI. The specific objectives of this study were to examine the coverage of CAPE Outcomes 2013 provided by the EILI; collect evidence supporting the reliability and validity of the EILI among pharmacy students; and determine the frequency distribution of pharmacy students across EILI measures.

\section{METHODS}

This analysis used a cross-sectional design and describes responses from subjects from two pharmacy programs, Regis University and the University of Minnesota, completing the EILI. ${ }^{20}$ By combining responses from these two schools, a diverse set of variables are included. Regis University School of Pharmacy, established in 2009, offers a minimum three-year pre-pharmacy/four-year pharmacy program. Regis University is a teaching-focused, private, Jesuit institution located in Denver, Colorado, with about 75 students per cohort. The University of Minnesota College of Pharmacy, established in 1892, has a minimum two-year pre-pharmacy/four-year pharmacy program. It is a research-intensive, public, dual-campus program, with about 105 students in the Twin Cities and 60 students in Duluth. Data from each institution were collected and then analyzed in the aggregate. The research was reviewed and approved as exempt by the institutional review boards of both institutions.

All data were collected from pharmacy students, who completed the EILI assessment as part of a course requirement. Each school attempted to include data from all students within a class. In this analysis, Regis had 79 of 82 third-year pharmacy students $(96.3 \%)$. Minnesota had 156 of 169 second-year students $(92.3 \%)$. The EILI was administered in different years at each institution because of the timing of the primary leadership course in each curriculum. This was determined to be acceptable for the study design since students would have had similar exposure to leadership topics at the time of administration. The overall response rate was $93.6 \%$, providing an overall total of 235 pharmacy student respondents from a pool of 251 possible respondents.

Following examination of a number of instruments, the EILI was selected for this study because it was specific to students, affordable, did not require training to administer or interpret, and combined measures of both leadership and emotional intelligence. The EILI uses 24 self-rated items to determine three facets (eight items for each facet) that contribute to the students' leadership. ${ }^{20}$ The three facets of EIL are consciousness of self (prioritizing the inner work of reflection and introspection and appreciating that self-awareness is a continual and ongoing process), consciousness of others (intentionally working with and influencing individuals and groups to bring about positive change), and consciousness of context (paying attention to how environmental factors and internal group dynamics affect the process of leadership). ${ }^{21}$ The items within each facet were originally developed after a qualitative search of the leadership and EI literature ${ }^{19}$ Each item on the EILI is rated on a scale of 1 to 5 in which $1=$ never and $5=$ always. Scores for the items are summed to provide a score for each of the three facets. Upon completion of the inventory, students gain an understanding of whether each facet is an area of strength, a likely opportunity for development, or a clear area for development.

A license was obtained for the instrument's use and to deliver the instrument online. All students received an email invitation to complete the EILI via the online survey system Qualtrics (Qualtrics, LLC, Provo, UT). Each respondent who completed the EILI received a report of his or her mean totals for the three facets immediately after submission. Each respondent was assigned a unique identifier for anonymity. A variable was added indicating school designation and the data from schools were 


\section{American Journal of Pharmaceutical Education 2017; 81 (2) Article 29.}

merged. All statistical analyses were conducted using STATA 14.0 (Stata Statistical Software, StataCorp LP, College Station, TX).

The EILI has been examined in a number of studies, which has resulted in a body of evidence regarding its validity and reliability. ${ }^{19,22-24}$ In constructing the instrument, four EI models were used to identify five aspects of EI that the EILI would measure. ${ }^{19}$ Each factor (or facet) of the EILI was found to have high internal consistency reliability (consciousness of context, $\alpha=.81$; consciousness of self, $\alpha=.73$; consciousness of others, $\alpha=.82$ ). ${ }^{25}$ As part of this study, the instrument analysis aimed to provide further evidence of validity, confirm its structure, and establish reliability among pharmacy students.

Following advice of Peeters and colleagues, ${ }^{26}$ additional evidence of the EILI's validity was pursued to specifically show the coverage and relevance of the EILI content to pharmacy students. Specifically, a crosswalk process was created to determine the degree of connectivity between each item of the EILI and 10 of the CAPE 2013 Outcomes in Domains 3 (Approach to Practice and Care) and 4 (Personal and Professional Development). Three of the authors, representing pharmaceutical science, social science, and pharmacy practice perspectives, independently determined whether a primary or secondary connection existed between each EILI item and each of the $10 \mathrm{CAPE}$ outcomes. These ratings were then used to determine a consensus with regard to primary and secondary connections. The connection between CAPE 2013 Outcome Domains and EILI was considered primary when there was a perceived direct and strong connection between the behaviors described in the outcome domain statement and the EILI item (ie, the EIL behavior would be required to achieve the competency). For example, the EILI item "Monitor how my emotions affect my interactions with others" would be required to fulfill the CAPE domain 4.1 Self-Awareness. A secondary connection signified a lesser connection than the primary connection. A secondary connection was defined as being implied or important to best practices in carrying out the competency but not required. Each EIL behavior was limited to one primary connection to the CAPE domains (eg, 4.1 SelfAwareness), but could have secondary connections to more than one domain (eg, 3.6 Communication and 4.4 Professionalism).

To examine the three established facets of the EILI within our student population, a confirmatory factor analysis was conducted. The confirmatory factor analysis ensured that the items that are associated with each of the three facets are somewhat related to one another and are appropriate to be collected together to provide a common result. ${ }^{27}$ Structural equation modeling was used to produce statistical values to determine the fit of each item within each of the facets. Two common statistical values are used in this analysis: the Root Mean Square Error of Approximation (RMSEA) index, which should be below .08, and a Standard Root Mean Residual (SRMR), which should be less than .05 to indicate a good model fit and less than .10 to be considered acceptable. ${ }^{28}$ The internal consistency reliability of each facet was determined by calculating a Cronbach's alpha for each item, with a value above .7 considered acceptable for internal consistency among items. $^{26,29}$

To understand the characteristics of students within pharmacy programs, descriptive statistics including frequency distribution and mean values were generated for each item of the EILI. Student response data were combined for both schools to calculate the overall mean, minimum, maximum scores, and the standard deviation for all students who took the EILI. Each of the three facets (context, self, and others) had a maximum point value of 40 , and the total score possible for all questions was 120 points. For ease of interpretation of the frequency distribution statistic, the items on the EILI were reduced from five to three categories; responses of never and infrequently were collapsed into a single category, responses of sometimes and frequently were collapsed into a single category; and responses of always were left as a category of its own. Collapsing the categories as described allowed us to identify items on which a proportion of the population may need improvement (as indicated by responses of never or infrequently) and those that excel on an item (as indicated by a response of always).

\section{RESULTS}

The EILI to CAPE Crosswalk (Table 1) showed that at least one connection (primary or secondary) existed between the EILI and all of the CAPE 2013 Outcomes in Domains 3 and 4 . Nine of the primary connections identified were in leadership (4.2). In addition, Interprofessional Collaboration (3.4) and Patient Advocacy (3.3) had many secondary connections to statements measured by the instrument (Table 1).

The confirmatory factor analysis and Cronbach's alpha statistics for each of the three facets indicated internal consistency among the items within each facet (Table 2). The items within the "consciousness of self" facet and "consciousness of others" facet indicated good model fits with both the SRMR and the RMSEA values. The items within the "consciousness of context" facet indicated a model fit with the SRMR value, however the RMSEA value of .1 was slightly higher than the .08 threshold value. Although this result does not fall under the recommended cutoff values, Marsh and colleagues contend that 
American Journal of Pharmaceutical Education 2017; 81 (2) Article 29.

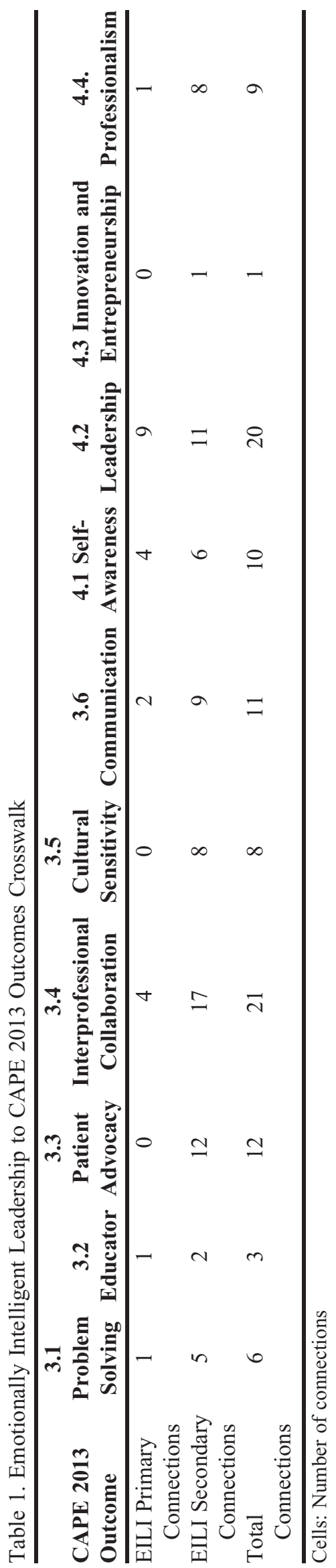

these rules are really guidelines and that values near the .08 threshold are reasonable errors of approximation. ${ }^{28}$ The Cronbach's alpha values for each of the three facets were above .7, which suggests internal consistency within each facet.

Table 3 describes the aggregate results for each of the three facets and the overall total mean score. Whereas, the means of the three facets do not differ from one another with any large quantity; among the three facets, the highest mean (31.5) was for the "consciousness of self" facet and the lowest mean (29.5) was for the "consciousness of context" facet. The average overall score on the EILI was 91.8 out of 120 possible points.

Table 4 displays the frequency distribution for each item on the instrument, sorted by facet. Within consciousness of context, $14.9 \%$ of respondents stated that they infrequently or never "think about how my leadership style aligns with group culture" and $11.5 \%$ infrequently/ never "identify external influences on the group." Within consciousness of self, $12.3 \%$ of respondents felt that they infrequently/never "work on my limitations." Within consciousness of others, $6.4 \%$ of respondents indicated that they infrequently/never "help others enhance their skills and abilities." In contrast, items of reported strength included $47.2 \%$ of respondents indicating that they always "follow through on my commitments" (consciousness of self) and $37.5 \%$ indicating that they always "work with others toward a shared goal" (consciousness of self).

\section{DISCUSSION}

This study examined the alignment between the EILI and the CAPE Outcomes 2013, the reliability and validity of the EILI among a pharmacy student population, and the frequency distribution of responses to items on the EILI. The EILI-CAPE crosswalk process provided evidence supporting the validity of the instrument and the confirmatory factor analysis allowed some certainty that the facets were reliable among the student population. Taken together, this information suggests that the instrument is a useful tool for the identification of emotionally intelligent leadership capacities among pharmacy students.

Ten CAPE Outcomes had either primary or secondary connections with the EILI instrument. The CAPE Outcome that had the highest number of total connections was outcome 3.4 Interprofessional Collaboration. This particular outcome is increasingly important to the education of pharmacists following release of the Interprofessional Education Collaborative's Core Competencies for Interprofessional Collaborative Practice (IPEC) $)^{30}$ and Standard 11 of ACPE Standards $2016 .{ }^{31}$ This instrument could be used to aid our instruction and coaching of students to become better members on interprofessional 
American Journal of Pharmaceutical Education 2017; 81 (2) Article 29.

Table 2. Confirmatory Factor Analysis of the Three Facets of the Emotionally Intelligent Leadership Inventory

\begin{tabular}{|c|c|c|c|c|c|}
\hline Factor & Item $^{\mathrm{a}}$ & Std. Coefficient & Cronbach's Alpha & RMSEA & SRMR \\
\hline \multirow[t]{9}{*}{ Consciousness of Context } & & & 0.78 & 0.1 & 0.06 \\
\hline & 1 & 0.48 & & & \\
\hline & 2 & 0.51 & & & \\
\hline & 5 & 0.51 & & & \\
\hline & 7 & 0.67 & & & \\
\hline & 9 & 0.43 & & & \\
\hline & 12 & 0.65 & & & \\
\hline & 16 & 0.63 & & & \\
\hline & 18 & 0.57 & & & \\
\hline \multirow[t]{9}{*}{ Consciousness of Self } & & & 0.74 & 0.07 & 0.05 \\
\hline & 3 & 0.43 & & & \\
\hline & 4 & 0.56 & & & \\
\hline & 6 & 0.54 & & & \\
\hline & 10 & 0.36 & & & \\
\hline & 13 & 0.49 & & & \\
\hline & 15 & 0.66 & & & \\
\hline & 19 & 0.67 & & & \\
\hline & 22 & 0.39 & & & \\
\hline \multirow[t]{9}{*}{ Consciousness of Others } & & & 0.79 & 0.07 & 0.04 \\
\hline & 8 & 0.49 & & & \\
\hline & 11 & 0.61 & & & \\
\hline & 14 & 0.40 & & & \\
\hline & 17 & 0.62 & & & \\
\hline & 20 & 0.60 & & & \\
\hline & 21 & 0.59 & & & \\
\hline & 23 & 0.61 & & & \\
\hline & 24 & 0.63 & & & \\
\hline
\end{tabular}

Abbreviations: RMSEA = root mean square error of approximation; $\mathrm{SRMR}=$ standard root mean residual

${ }^{\text {a }}$ See Table 4 for item text

teams. For example, EILI items "take time to understand the informal traditions of the group" and "learn the expressed and implicit values of the group" could be used to evaluate the objectives in IPEC Competency Domain 4, Teams and Teamwork ${ }^{30}$ and "understand how the group members relate to one another" aligns with the statements in IPEC Competency Domain 2, Roles/Responsibilities. ${ }^{30}$

The CAPE Outcome 4.2 Leadership had the second highest number of links with items on the EILI, which was expected because many of the EILI items were derived from documented aspects of leadership. ${ }^{19}$ Eleven leadership competencies have been identified for pharmacy students around the areas of leadership knowledge, personal leadership commitment, and leadership skill development. ${ }^{32}$ The EILI could be used to aid in assessing aspects of these leadership competencies. For example, the EILI item "align differing viewpoints within the group" connects with the leadership competency, "develop a shared vision for an initiative or project." 32

There were also a number of other CAPE Outcomes with multiple connections with items on the EILI, including
3.3 Patient Advocacy, 3.6 Communication, and 4.1 SelfAwareness. In a discussion of EI in medical education, Cherry and colleagues argue EI is relevant to developing the communication skills of a practitioner, specifically to understanding how to identify and react to a patient's emotions. ${ }^{5}$ In pharmacy, the connection between EI and communication was directly explored by aligning an EI framework with a communication course. This study identified two themes: (1) students realized it was important to be competent in EI, and (2) EI knowledge would be helpful to students when they were working with patients to achieve desired outcomes. ${ }^{33}$ The EILI instrument could be used as a tool to further explore the connection between EI and student competency on the Communication, Patient Advocacy and Self-Awareness CAPE Outcomes.

While using EI in educational settings has value on its own, it has been recommended that the results be interpreted within a larger context of student performance on other skills or tasks, such as OSCE scores. ${ }^{5}$ In this study, students took the EILI and reviewed their results as an independent activity with follow-up discussion and group 


\section{American Journal of Pharmaceutical Education 2017; 81 (2) Article 29.}

Table 3. Aggregate Descriptive Statistics for the EILI

Responses

\begin{tabular}{llcc}
\hline EILI Facet & Mean (SD) & Lowest Score & Highest Score \\
\hline Context (40) & $29.5(4.1)$ & 14 & 40 \\
Self (40) & $31.5(3.6)$ & 22 & 40 \\
Others (40) & $30.7(3.8)$ & 20 & 40 \\
Total (120) & $91.8(10.2)$ & 61 & 120 \\
\hline
\end{tabular}

work within the classroom. Administering the assessment and interpreting the results within the context of other educational activities, especially those related to interprofessional collaboration, leadership, or communication, would provide a more comprehensive picture of EI and its importance for students.

Additional student data from this instrument, as well as other sources, would allow us to identify pharmacy student strengths and weaknesses more definitively. However, data from this group of students may provide insights into potential development needs and some guidance for future investigations. On average, respondents scored approximately 10 points below the maximum available points of 40 for each facet (Table 3). This would suggest that, on average, pharmacy students have a moderate range of abilities in all three facets. The instrument describes three ranges of scores for each facet: a healthy range of abilities (35-40), where the subject intentionally demonstrates the various capacities and the facet is an area of strength; a moderate range (26-34), where the subject intentionally demonstrates some of the capacities but there are likely opportunities for development; and a limited range (8-25), where the subject does not see themselves as intentionally demonstrating the capacities and the facet is a clear area for development. ${ }^{20}$ In short, there is potential for further growth in all three facets.

The responses also identify capacities that pharmacy students self-report using infrequently (Table 4). Within the consciousness of context facet, 3.4\% reported that they infrequently or never "recognize the patterns of behavior in the group," and $14.9 \%$ self-reported that they infrequently or never "think about how my leadership style aligns with group culture." These results signal the potential utility of activities that aid students in building awareness of context and in examining their personal approach given the context.

In the "consciousness of self" facet, responses were lower for "work on my own limitations" $(12.3 \%$, infrequently/never) and "reflect on how my actions align with my values" (9.8\%, infrequently/never), both of which may be critical to future success. In particular, Kouzes and Posner have argued that to be a credible leader you first need to clarify your own values ${ }^{34}$ and that one's actions need to align with one's values. ${ }^{17}$
Within the consciousness of others facet, lower-rated capacities included "help others enhance their skills and abilities" (6.4\% infrequently/never). In a Delphi study of pharmacy leadership instructors, "assisting others in developing leadership abilities" was a competency that did not reach consensus among the group as required of pharmacy students. However, due to the limited number of rounds, it was not clear whether the topic required further discussion and refinement or whether the competency was considered inappropriate for entry-level pharmacists. ${ }^{32}$ The 2008-2009 Argus Commission report on building sustainable leadership development in pharmacy educa$\operatorname{tion}^{35}$ draws attention to the leadership practice of "Enable Others to Act"17 and states that "perhaps the most essential skills to inculcate in our student leaders are the ability to foster collaboration, delegate and strengthen others to contribute..." [emphasis ours]. Pharmacy students' ability to develop others requires more debate and investigation.

The use of this instrument has some limitations. On the EILI, groups are referred to on several items (eg, "understand the priorities of others in the group" and "consider the needs of others in the group"). The concept of group could have been interpreted to mean those individuals that the pharmacy student worked with closely or their interprofessional health care team. It could also have been interpreted to mean the patients who they serve. The interpretation of specific items related to the "group" on the EILI could have affected the responses. The EILI is also a self-reported instrument, which means it may or may not reflect the students' actual behaviors. Often selfassessment data does not correlate with external assessments, ${ }^{36}$ yet it is a necessary skill for a professional to have and can supplement other forms of teaching and assessment in a pharmacy curriculum. ${ }^{37}$ Motycka and colleagues assert that pharmacy students can learn selfassessment and summarize recommendations from the literature on how it can be improved. ${ }^{37}$ A systematic review of medical education literature suggests EI can be improved if structured education sessions are also provided. ${ }^{38}$ Future work involving use of the EILI, combined with targeted educational activities, could be designed to examine changes in student EI. In addition to targeted educational activities, the role of advisers or career coaches in improving EI could be explored. In addition, to further support interprofessional development, it may also be helpful to examine pharmacy student EI and EI in other health professions students.

The authors of the EILI have recently produced version 2 of the instrument, which now consists of 57 total items to be rated by students. Each facet now contains a varying number of capacities (self, eight; others, nine; 
American Journal of Pharmaceutical Education 2017; 81 (2) Article 29.

Table 4. Number and Percent of Student Responses by EILI Facet and Item

\begin{tabular}{|c|c|c|c|c|}
\hline Facet and Statement ${ }^{\dagger}$ (Item \#) & $\begin{array}{l}\text { Never/Infrequently, } \\
\text { No. }(\%)\end{array}$ & $\begin{array}{c}\text { Sometimes/Frequently, } \\
\text { No. }(\%)\end{array}$ & $\begin{array}{l}\text { Always, } \\
\text { No. }(\%)\end{array}$ & Mean Score $^{\mathrm{a}}$ \\
\hline \multicolumn{5}{|l|}{ Consciousness of Context } \\
\hline $\begin{array}{l}\text { Recognize the patterns of behavior in } \\
\text { the group (18) }\end{array}$ & $8(3.4)$ & $173(73.6)$ & $54(23.0)$ & 4.0 \\
\hline $\begin{array}{l}\text { Tailor my leadership style to the } \\
\text { situation (5) }\end{array}$ & $16(6.8)$ & $171(72.8)$ & $48(20.4)$ & 3.8 \\
\hline $\begin{array}{l}\text { Understand how the group members } \\
\text { relate to one another }(9)\end{array}$ & $12(5.1)$ & $192(81.7)$ & $31(13.2)$ & 3.8 \\
\hline $\begin{array}{l}\text { Learn the expressed and implicit } \\
\text { values of the group }(2)\end{array}$ & $10(4.3)$ & $198(84.3)$ & $27(11.5)$ & 3.7 \\
\hline $\begin{array}{l}\text { Take time to understand the informal } \\
\text { traditions of the group (1) }\end{array}$ & $14(6.0)$ & $192(81.7)$ & $29(12.3)$ & 3.7 \\
\hline $\begin{array}{l}\text { Understand how the group's } \\
\text { environment influences my } \\
\text { leadership style ( } 7 \text { ) }\end{array}$ & $14(6.0)$ & $196(83.4)$ & $25(10.6)$ & 3.7 \\
\hline $\begin{array}{l}\text { Think about how my leadership } \\
\text { style aligns with group culture (12) }\end{array}$ & $35(14.9)$ & $167(71.1)$ & $33(14.0)$ & 3.5 \\
\hline $\begin{array}{l}\text { Identify external influences on the } \\
\text { group (16) }\end{array}$ & $27(11.5)$ & $184(78.3)$ & $24(10.2)$ & 3.5 \\
\hline \multicolumn{5}{|l|}{ Consciousness of Self } \\
\hline Follow through on my commitments (10) & $-(-)$ & $124(52.8)$ & $111(47.2)$ & 4.4 \\
\hline Work with others toward a shared goal (22) & $1(0.4)$ & $146(62.1)$ & $88(37.5)$ & 4.3 \\
\hline Establish a positive tone (13) & $4(1.7)$ & $160(68.1)$ & $71(30.2)$ & 4.1 \\
\hline $\begin{array}{l}\text { Monitor how my emotions affect my } \\
\text { interactions with others (3) }\end{array}$ & $9(3.8)$ & $169(71.9)$ & $57(24.3)$ & 3.9 \\
\hline Capitalize on my strengths (6) & $5(2.1)$ & $180(76.6)$ & $50(21.3)$ & 3.9 \\
\hline Improve my abilities (15) & $7(3.0)$ & $180(76.6)$ & $48(20.4)$ & 3.9 \\
\hline $\begin{array}{l}\text { Reflect on how my actions align with } \\
\text { my values (19) }\end{array}$ & $23(9.8)$ & $176(74.9)$ & $36(15.3)$ & 3.6 \\
\hline Work on my limitations (4) & $29(12.3)$ & $183(77.9)$ & $23(9.8)$ & 3.4 \\
\hline \multicolumn{5}{|l|}{ Consciousness of Others } \\
\hline $\begin{array}{l}\text { Think about how my decisions are received } \\
\text { by group members (14) }\end{array}$ & $3(1.3)$ & $158(67.2)$ & $74(31.5)$ & 4.1 \\
\hline $\begin{array}{l}\text { Listen carefully to what is and isn't being } \\
\text { said by group members (21) }\end{array}$ & $2(0.9)$ & $175(74.5)$ & $58(24.7)$ & 4.0 \\
\hline Consider the needs of others in the group (17) & $7(3.0)$ & $180(76.6)$ & $48(20.4)$ & 4.0 \\
\hline Work to build a sense of team (11) & $10(4.3)$ & $182(77.5)$ & $43(18.3)$ & 3.9 \\
\hline Work to resolve conflicts within the group (23) & $14(6.0)$ & $175(74.5)$ & $46(19.6)$ & 3.8 \\
\hline $\begin{array}{l}\text { Understand the priorities of others in the } \\
\text { group (20) }\end{array}$ & $9(3.8)$ & $199(84.7)$ & $27(11.5)$ & 3.7 \\
\hline Align differing viewpoints within the group (24) & $14(6.0)$ & $197(83.8)$ & $24(10.2)$ & 3.6 \\
\hline Help others enhance their skills and abilities (8) & $15(6.4)$ & $196(83.4)$ & $24(10.2)$ & 3.6 \\
\hline
\end{tabular}

${ }^{\dagger}$ Shankman ML, Allen SJ, Facca TM. Emotionally Intelligent Leadership for Students: Inventory. San Francisco, California: Jossey-Bass; 2010. ${ }^{20}$ Items reprinted with permission. Copyright (c) 2010 by Marcy Levy Shankman, Scott J. Allen, and Tina Facca. All rights reserved

${ }^{a}$ Likert responses: 1 = never, $2=$ infrequently, $3=$ sometimes, $4=$ frequently, $5=$ always

context, two) and students rate three statements for each capacity on a seven-point Likert-type scale. ${ }^{39}$ For example, within the facet consciousness of others, one of the capacities is Building Teams: "Working with others to accomplish a shared purpose." This capacity is assessed by three statements including how often the student emphasizes team goals, builds strong teams, and works well with others toward a shared goal. The scoring process is also more involved in that the ratings on these three statements are combined to give the overall score for building teams. This scoring method provides students more information on all the capacities, in addition to their scores on each capacity relative to others within the same facet. Given the unique combination of EI and leadership in the EIL model and the 


\section{American Journal of Pharmaceutical Education 2017; 81 (2) Article 29.}

connections to a breadth of CAPE Outcomes, further exploration of the use of version 2 of the EILI in pharmacy students is warranted.

\section{CONCLUSION}

The Emotionally Intelligent Leadership Inventory can be used as a tool to provide input to individual students, aiding in their personal development, as well as for creating conversation in the classroom. In addition, it may provide colleges and schools with input on several competencies in the CAPE 2013 Outcomes, such as interprofessional communication and leadership. Initial evidence supporting validity and reliability for use within pharmacy students was collected. Students' responses on the EILI identify areas of strength and areas for development, and this may aid pharmacy educators in designing educational activities. Weighing this evidence with other evidence, including student performance, is advised. Further exploration of the EILI's use with pharmacy students is warranted.

\section{REFERENCES}

1. Gardner H. Frames of Mind: The Theory of Multiple Intelligences. New York, NY: Basic Books; 2011.

2. Mayer JD, Salovey P, Caruso DR. Emotional intelligence: theory, findings, and implications. Psychol Inq. 2004;15(3):197-215.

3. Goleman D. Working with Emotional Intelligence. New York, NY: Bantam Books; 1998.

4. Goleman D. Emotional Intelligence. New York, NY: Bantam Books; 1995.

5. Cherry MG, Fletcher I, O'Sullivan H, Dornan T. Emotional intelligence in medical education: a critical review. Med Educ. 2014;48(5):468-478.

6. Medina MS, Plaza CM, Stowe CD, et al. Center for the Advancement of Pharmacy Education (CAPE) Educational Outcomes 2013. Am J Pharm Educ. 2013;77(8):Article 162. 7. Accreditation Council for Pharmacy Education. Accreditation standards and guidelines for the professional program in pharmacy leading to the doctor of pharmacy degree. 2007. https://www.acpe-accredit.org/pdf/FinalS2007Guidelines2.0. pdf.

8. Nelson MH, Fierke KK, Sucher BJ, Janke KK. Including emotional intelligence in pharmacy curricula to help achieve CAPE outcomes. Am J Pharm Educ. 2015;79(4):Article 48.

9. Hammer DP, Berger BA, Beardsley RS, Easton MR. Student professionalism. Am J Pharm Educ. 2003;67(3):Article 96.

10. Cherry MG, Fletcher I, O'Sullivan H. Validating relationships among attachment, emotional intelligence and clinical communication. Med Educ. 2014;48(10):988-997.

11. Cherry MG, Fletcher I, O’Sullivan H. Exploring the relationships among attachment, emotional intelligence and communication. Med Educ. 2013;47(3):317-325.

12. Chew BH, Zain AM, Hassan F. Emotional intelligence and academic performance in first and final year medical students: a cross-sectional study. BMC Med Educ. 2013;13(1):44. 13. George JM. Emotions and leadership: the role of emotional intelligence. Hum Relations. 2000;53(8):1027-1055.
14. Prati LM, Douglas C, Ferris GR, Ammeter AP, Buckley MR. Emotional intelligence, leadership effectiveness, and team outcomes. Int J Organ Anal. 2003;11(1):21-40.

15. Wong CS, Law KS. The effects of leader and follower emotional intelligence on performance and attitude: an exploratory study.

Leader Quar. 2002;13(2):243-274.

16. Traynor AP, Boyle CJ, Janke KK. Guiding principles for student leadership development in the doctor of pharmacy program to assist administrators and faculty members in implementing or refining curricula. Am J Pharm Educ. 2013;77(10):Article 221.

17. Kouzes JM, Posner BZ. The Student Leadership Challenge: Five Practices for Becoming an Exemplary Leader. 2nd ed. San Francisco, CA: Jossey-Bass; 2014.

18. Romanelli F, Cain J, Smith KM. Emotional intelligence as a predictor of academic and/or professional success. Am J Pharm Educ. 2006;70(3):Article 69.

19. Allen SJ, Shankman ML, Miguel RF. Emotionally intelligent leadership: an integrative, process-oriented theory of student leadership research and theory. J Leadersh Educ. 2012;11(1):177203.

20. Shankman ML, Allen SJ, Facca TM. Emotionally Intelligent Leadership for Students: Inventory. San Francisco, CA: Jossey-Bass; 2010.

21. Shankman ML, Allen SJ. Emotionally Intelligent Leadership: A Guide for College Students. San Francisco, CA: Jossey-Bass; 2008. 22. Facca TM, Allen SJ. Using cluster analysis to segment students based on self-reported emotionally intelligent leadership behaviors. J Leadersh Educ. 2011;10(2):72-96.

23. Haber P, Allen SJ, Facca T, Shankman ML. College students' emotionally intelligent leadership: an examination of differences by student organization involvement and formal leadership roles. Int $J$ Leadersh Stud. 2012;7(2):246-265.

24. Shankman ML, Haber P, Facca T, Allen SJ. Gender and leadership through the lens of emotionally intelligent leadership. Leadersh Rev. 2010;10(Summer):88-103.

25. Shankman ML, Allen SJ. Emotionally Intelligent Leadership for Students: Facilitation Guide. San Francisco, California: Jossey-Bass; 2010 .

26. Peeters MJ, Beltyukova SA, Martin BA. Educational testing and validity of conclusions in the scholarship of teaching and learning. Am J Pharm Educ. 2013;77(9):Article 186.

27. Mulaik S. Confirmatory factor analysis. In: Nesselroade J, Cattell R, eds. Handbook of Multivariate Experimental Psychology SE - 7. Perspectives on Individual Differences. Springer US; 1988:259-288. 28. Marsh HW, Hau K-T, Wen Z. In search of golden rules: comment on hypothesis-testing approaches to setting cutoff values for fit indexes and dangers in overgeneralizing $\mathrm{Hu}$ and Bentler's (1999) findings. Struct Equ Model: Multidiscip J. 2004;11(3):320341.

29. Nunnally JC. Assessment of reliability. In: Pscyhometric Theory. 2nd ed. New York, NY: McGraw-Hill Book Co.; 1978:245-246. 30. Interprofessional Education Collaborative Expert Panel. Core competencies for interprofessional collaborative practice: report of an expert panel. Washington, DC; 2011. https://ipecollaborative.org/ uploads/IPEC-Core-Competencies.pdf.

31. Accreditation Council for Pharmacy Education. Accreditation standards and key elements for the professional program in pharmacy leading to the doctor of pharmacy degree. Standards 2016. https:// www.acpe-accredit.org/pdf/Standards2016FINAL.pdf.

32. Janke KK, Traynor AP, Boyle CJ. Competencies for student leadership development in doctor of pharmacy curricula to assist 


\section{American Journal of Pharmaceutical Education 2017; 81 (2) Article 29.}

curriculum committees and leadership instructors. Am J Pharm Educ. 2013;77(10):Article 222.

33. Lust E, Moore FC. Emotional intelligence instruction in a pharmacy communications course. Am J Pharm Educ. 2006;70(1): Article 6. http://www.pubmedcentral.nih.gov/articlerender.fcgi? artid $=1636903 \&$ tool $=$ pmcentrez\&rendertype $=$ abstract.

34. Kouzes JM, Posner BZ. Credibility: How Leaders Gain and Lose It, Why People Demand It. San Francisco, CA: Jossey-Bass; 2003.

35. Kerr RAB, Beck DE, Doss J, et al. Building a sustainable system of leadership development for pharmacy: Report of the 2008-09

Argus Commission. Am J Pharm Educ. 2009;73(Suppl):Article S5. 36. Davis DA, Mazmanian PE, Fordis M, Van Harrison R, Thorpe KE, Perrier L. Accuracy of physician self-assessment compared with observed measures of competence: a systematic review. JAMA. 2006;296(9):1094-1102.

37. Motycka CA, Rose RL, Ried LD, Brazeau G. Self-assessment in pharmacy and health science education and professional practice. Am $J$ Pharm Educ. 2010;74(5):Article 85.

38. Cherry MG, Fletcher I, O'Sullivan H, Shaw N. What impact do structured educational sessions to increase emotional intelligence have on medical students? BEME Guide No. 17. Med Teach. 2012;34(1):11-19. http://www.ncbi.nlm.nih.gov/pubmed/22250672. Accessed August 29, 2014.

39. Shankman ML, Allen SJ, Haber-Curran P. Emotionally Intelligent Leadership: A Guide for Students. John Wiley \& Sons; 2015. 